\title{
Natural and anthropogenic extensive destruction of the spruce forest community of the European part of Russia: main trends of biodiversity dynamics
}

\author{
Nina Ulanova*, and Andrei Kaplevsky \\ Department of Ecology and Plant Geography, Faculty of Biology, Moscow State University \\ 119234, Moscow, Russia
}

\begin{abstract}
We analyzed the main trends of the change in the species richness of plant communities after catastrophic natural (beetle outbreaks, windfalls) and anthropogenic (clear cutting) disturbances. We examined the dynamics of the structural diversity of species richness of herb-dwarf scrubs layer with different reforestation technologies after the death of spruce stands. The study of similarity and ordination of vegetation showed the proximity of the undamaged forest to the unharvested stand, and the difference of these plant communities from clear-cut. The main determining factor of species richness was the intensity of plant community disturbance after catastrophes. We analyzed the reforestation dynamics of plant communities after catastrophic disturbances. Clear cutting led to the formation of grassy communities with a sharp increase in the species and structural diversity of plant community.
\end{abstract}

\section{Introduction}

The problem of conservation of forest biodiversity is one of the most important challenges in biology and ecology in 20-21 centuries and the central task of wildlife conservation. All anthropogenic (clear-cutting, large area forest fires, industrial pollution) and natural (massive insect infestations, catastrophic windfalls) disturbances are considered to be negative factors leading to a reduction in biodiversity [1]. The large-scale death of forests leads to the reduction of diversity of biotopes, phytochors, and plant communities, the extinction of species and the reduction of their intraspecific genetic diversity. These conventional ideas are based on the comparison of data from different researchers, construction of spatiotemporal patterns, etc. However, identification of change patterns in species composition of communities can only be done by monitoring of the biodiversity of permanent sample plots in a series of plant communities along a relief gradient within a limited area (phytocatenae) for a long period of times after catastrophic disturbances [2].

\footnotetext{
* Corresponding author: NUlanova@,mail.ru
} 
We focused on an understudied aspect - the dynamics of plant species composition (alpha-diversity) in spruce forests of southern taiga and mixed coniferous-leaved forests of European Russia after "catastrophic" disturbances.

The natural environmental mechanism of the decay of spruce forest stand (which is the final stage of the dynamics of spruce plant communities at the final stage of succession in the European part of Russia) is implemented in catastrophic windfalls, fires or dead-wood patches during outbreaks of eight-dentated bark beetle (Ips typographus L.).

\section{The intensity of disturbances in plant communities after natural and anthropogenic disasters}

Catastrophic natural phenomena that cause the death of spruce forests create various scales of disturbance (Fig. 1). During fires, a significant portion of stands and low-growing vegetation dies, and a very wide range of soil damage is observed. In the case of catastrophic windfalls, the scale of the loss of the stand and the ground cover varies, and the soil cover damage is minor [3]. With partial preservation of the forest stand and undergrowth in windfalls, only a redistribution of dominant species with a slight change in the species composition occurs in the herb-dwarf shrubs layer [2, 4]. In areas of spruce forests drying up during outbreaks of the eight-toothed bark beetle, the soil and ground cover remain mostly intact, but the proportion of dead spruce trees varies from 0 to $100 \%$. The degree of disturbance of ecosystems during disasters leading to the destruction of spruce forests determines the rate of recovery of vegetation in areas damaged by fires, windfalls, and in the epicenters of spruce desiccation

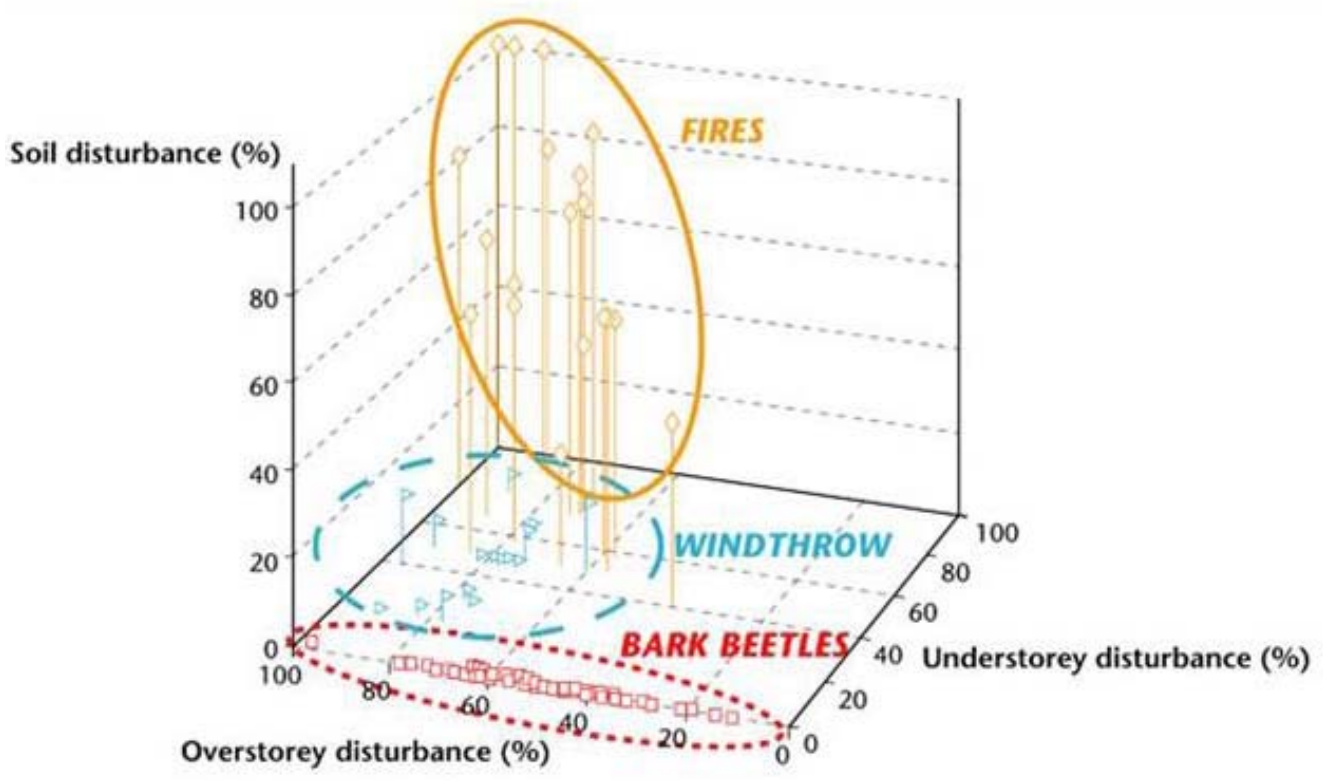

Fig. 1. The intensity of the destruction of the forest stand, ground cover and soil in plant communities after natural catastrophes (fire, massive windfall, outbreaks of bark beetle) [5].

\section{Increase of biodiversity: species richness and structural diversity}

Natural and anthropogenic disasters lead to transformations of the original plant communities of different intensity. As a result, an increase in biodiversity in new 
communities occurs; in areas of deadwood spruce it is insignificant, and it is higher in areas of catastrophic windfalls. When spruce stands (not just dead trees) are completely destroyed during clear-cutting, there is a radical change in the soil cover [6] and a transformation of forest communities into grass and shrub communities, which leads to a radical change in the vegetation cover. In newly formed grassy communities, biodiversity increases dramatically due to emergence of non-forest species [2]. In addition, a meta-analysis of the results of 238 biodiversity studies in various forests around the world found an increase in vascular plant species richness following catastrophic windfalls and stand loss due to bark beetle outbreaks and logging [7].

Let us consider as an example the changes in vegetation in the zones of spruce desiccation in 2012 in the western part of the Moscow region (Zvenigorod biological station of Moscow State University).

In 2013, we established three permanent sample plots of the same size $\left(800 \mathrm{~m}^{2}\right)$ in a spruce-weaselsnout forest: one in an area with the spruce forest stand that died in 2012 (bark beetle infection), one in an area of clear cutting of deadwood in the winter of 201213 , and one in an area with living spruce tree stand (control). The studies were conducted in August 2014, 2015, and 2016 using the same methodology. Three transects of $40 \mathrm{~m}$ length and $40 \mathrm{~cm}$ width each were made on the trial plots. The frequency of species in the herbdwarf shrubs layer was studied at each meter of the transect, using a rigid frame $40 \times 100$ $\mathrm{cm}$ in size, divided into $20 \times 20 \mathrm{~cm}$ squares by removable threads.

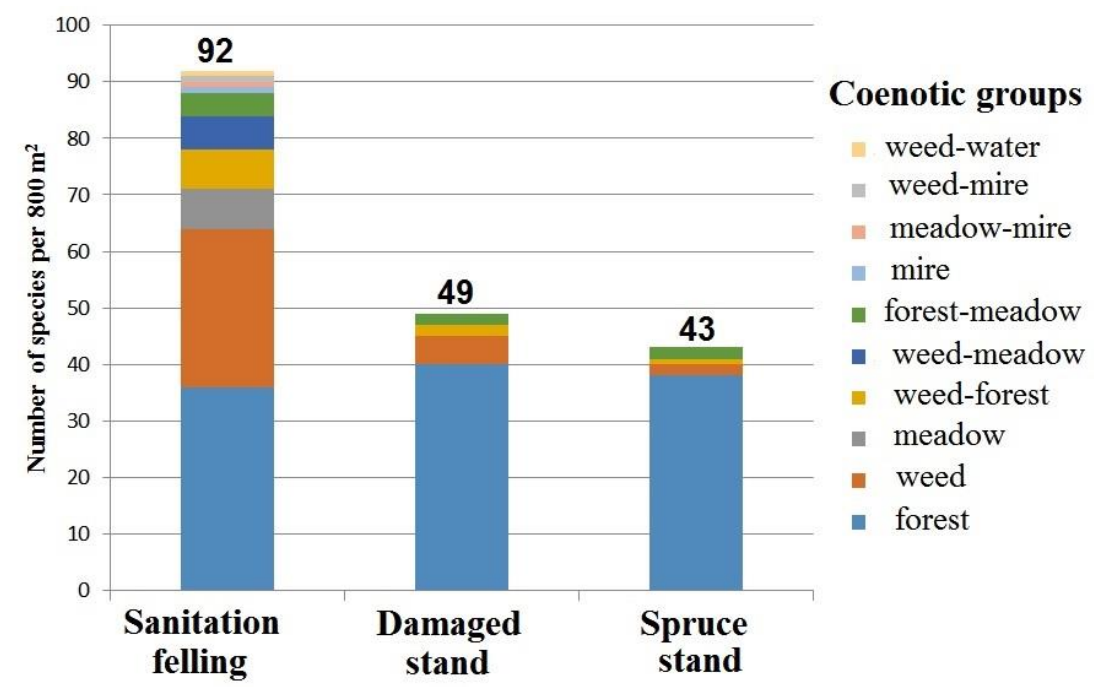

Fig. 2. The coenotic structure of the species richness of the herb-dwarf scrubs layer in the spruceweaselsnout stand (control), in the second year after the death of the forest stand with the sanitation felling of deadwood and with the preservation of the deadwood (damaged stand).

In spruce deadwood forest, species retained their dominance in the herb-dwarf shrubs layer (Fig. 2). After snagging, the floristic composition of the herb-dwarf shrubs layer increased by 2 times, compared to the undisturbed spruce stand, as a result of the death of the herb-dwarf shrubs layer, disturbances of moss and soil cover during the wood transportation, burning of cuttings and subsequent introduction of new species. Dominance passed on to other species. As a result of significant soil disturbances, patchiness of the herb-dwarf shrubs layer became very high.

The coenotic spectrum of the herb-dwarf shrubs layer in the spruce forest after the death of spruce trees corresponds to the spectrum of the original forest (Fig. 2). During the second year, there was a change in the frequency of species in the herb-dwarf shrubs layer and 
species were introduced of new coenotic group typical for the original forest. The frequency of moss cover species decreased due to shading from growing hazel shrubs. In the clearcut, the increase in the number of coenotic groups was doubled by the introduction of herbaceous species and mosses that were not characteristic of the original community. In the slash area, the proportion of forest species significantly decreased, and the proportion of weed, meadow and weed-meadow species increased. The type of the plant community of the slash areas can be characterized as forest-meadow.

\section{Regenerative dynamics of plant communities after catastrophic disturbances}

Significant disturbance of plant communities and soils leads to the following types of succession: demutational, secondary incomplete, and quasipervical. Changes in vegetation depend on the initial forest type. Thus, in spruce-blackberry and spruce-blackberryblackgrass forests in the Moscow region, the successions undergo a stage with rowan forests with spruce undergrowth. In spruce-aspen and complex spruce forests, the demutations pass through the stage of linden and maple forests with spruce undergrowth. In complex spruce forests with hazel, incomplete secondary succession ends in hazel shrub forest

An alternative method of forest management (preservation of dead wood and natural regeneration) is possible only in forests with nature conservation status. Preservation of dead wood and wind-blown areas in spruce forests leads to natural regeneration, which preserves forest plant communities and changes only the ratio of dominant species in the stand. As a result, mixed stands of broad-leaved species with high resistance to forest pests and diseases are formed. Complex forests replace monocultures of spruce, which contributes to the restoration of forest diversity characteristic of the coniferous-leaved forest zone. Such natural forests are most likely characteristic of the coniferous-leaved forest zone.

Forest management in spruce forests requires clear-cutting of dead stands in case of bark beetle outbreaks, as well as clearing areas of catastrophic wind-throw and fires. Massive use of clearcuts in the last ten years has led to an increase in the area of clearcuts, on which grass communities have formed. Biodiversity in the new herbaceous communities increases sharply due to the presence of non-forest species [2]. From a biologist's point of view, this process cannot be considered negative for nature. If our ideology requires an increase in biodiversity, the formation of herbaceous vegetation is the best solution. Several publications that have appeared in recent years raise the question of the importance of the first stages of succession to increase forest biodiversity $[7,8,9,10]$.

\section{References}

1. A.S. Isaev, Monitoring of biological diversity of Russian forests: methodology and methods. (Science, Moscow, 2008).

2. N.G. Ulanova, Herald of TVGU. Series: Biology and Ecology, 3, 317-335 (2018)

3. N.G. Ulanova, Forest Ecology and Management, 135(1-3), 155-167 (2000)

4. N.G. Ulanova and O.V. Cherednichenko, Izvestia of the Samara Scientific Center of the Russian Academy of Sciences, 14(1-5), 1399-1402 (2012).

5. P.J. Burton, BC Journal of Ecosystems and Management, 9(3), 9-13 (2008).

6. A.A. Dymov, Eurasian Soil Science, 7, 787-798 (2017)

7. S. Thorn, C. Bässler and R. Brandl, Journal of Applied Ecology, 55, 279-289 (2018) 
8. M.E. Swanson, J.F. Franklin, Ch.M. Crisafulli, D.A. Della Sala, R.L. Hutto, D.B. Lindenmayer and Fr.J. Swanson, Frontiers in Ecology and the Environment, 9(2), 117125 (2011)

9. D.P. Blair, L.M. McBurney, W. Blanchard, S.C. Bank and D.B. Lindenmaye, Ecological Applications, 26, 2280-2301 (2016)

10. P.J. Fornwalt, Ch.C. Rhoades, R.M. Hubbard, R.L.Harris,. A.M. Faist and W.D. Bowman, Forest Ecology and Management, 409, 84-93 (2018) 